\title{
Inspiration of Astronomy in the Movies: a History of a Close Encounter
}

\author{
Beatriz García, Estela Reynoso, Silvina Pérez Alvarez and Raúl \\ Gabellone
}

\begin{abstract}
The connection between astronomy and an independent, widespread cultural expression like cinematography is of particular interest within the context of the Inspiration of Astronomical Phenomena. Astronomy has caught the interest of the seventh art since its birth, early in the twentieth century. In this paper we go through a collection of movies that reveal how astronomy and astronomers are perceived by society. We notice the influence of the progress achieved in astronautics in the second half of the past century, and how interplanetary or even intergalactic travels have become a recurrent issue. In many cases, astronomical facts are rigorously treated, but several other times, serious mistakes are transmitted. Biographical movies based on astronomical celebrities are rare, but some are masterpieces, like Giordano Bruno by Giuliano Montaldo, or Galileo Galilei by Liliana Cavani. In this sense the astronomers, as main characters in cinema, support the idea of the scientist as everyman, connected with life and, in many cases, with a sense of social responsibility. From the analysis of more than a hundred movies, we can see that this particular manifestation of art, which involves science and technology, can be used not only to reproduce astronomical events, transmit a message or reproduce a particular epoch of science history, but also to teach, to develop a critical faculty when faced with information from the media, and to show that astronomical facts can be as interesting, relevant, dramatic, happy or funny as real life.
\end{abstract}

\section{Introduction}

Since its inception, cinema has been interested in astronomy. ${ }^{1}$ As early as in 1902, George Méliès began, with 'A Trip to the Moon', a long history

1 For background on astronomy and cinema see 'The Internet Movies Data Base’ at http://us.imdb.com [accessed 30 January 2011]; Phil Plait, 'Bad Astronomy’at http://www.badastronomy.com/bad/movies/index.html; T. Rogers, 'Insultingly Stupid Movie Physics' at

http://intuitor.com/moviephysics/index.html [accessed 30 January 2011]; N.

Beatriz García, Estela Reynoso, Silvina Pérez Alvarez and Raúl Gabellone, 'Inspiration of astronomy in the movies: a history of a close encounter', eds. Nicholas Campion and Rolf Sinclair, Culture and Cosmos, Vol. 16 nos. 1 and 2, 2012, pp. 357-371. www.CultureAndCosmos.org 
358 Inspiration of astronomy in the movies: a history of a close encounter

of the inclusion of our discipline in the movies. Méliès’ film was the first to show a journey beyond the Earth. A group of elegantly dressed astronauts blasts off on a giant shell before a delegation of cheerleaders. At the moon, they encounter a hostile 'Selenite' civilization from which they manage to escape by jumping off a cliff with the ship and, in a free interpretation of the law of gravity, the spacecraft falls safely into the sea, in the middle of planet Earth (See Figure 1). The cinema was used, in addition, as a technological resource to film the transit of Venus in 1882. This is probably the first scientific movie in history. ${ }^{2}$

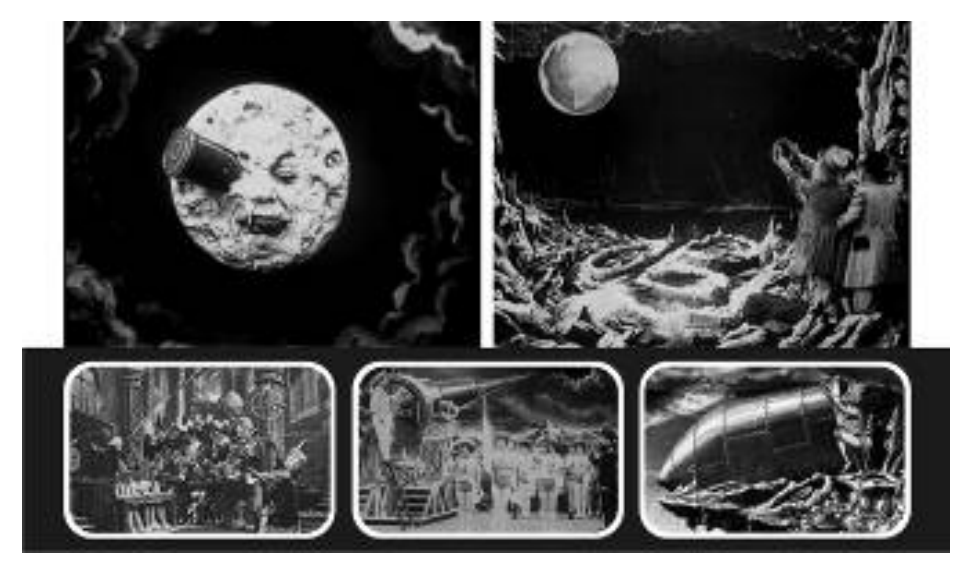

Figure 1. George Melies, A Trip to the Moon (1902)

Throughout the twentieth century fictional travel in space was a recurring topic in films, often treated as stories of space cowboys. In 'Serenity', this description fits literally. Arguably, the icon of space adventures is 'Star Wars', a story set on planets in remote galaxies, with advanced technology unknown to us. 'Star Wars' clearly shows the influence of

Travers, 'Sci-Fi Science Blunders Hall of Fames; Dedicated to documenting and commemorating bad science in TV \& Movie SF at http://sfblunders.wordpress.com [accessed 30 January 2011].

2 R. de Freitas Mourao, 'The Brazilian contribution to the observation of the transit of Venus, Transits of Venus: New Views of the Solar System and Galaxy', Proceedings of the International Astronomical Union, ed. D.W. Kurtz, Vol. 2004 No. IAU196 (2004): pp. 154-160; Capdevila, D., Gangui, A., Linares Moreau, M., Mayochi, M., El revolver fotografico: ¿un precursor del cine? at http://www.cielosur.com/notas anteriores/alejandro.php [accessed 30 January 2011].

Culture and Cosmos 

and Raúl Gabellone

another classic, 'Flash Gordon'. The first film of this saga appeared in 1936, with a remake in 1980. Following the same trend, we find 'Battlestar Galactica', where a civilization at risk is led by Commander Adama to a distant planet where they will begin a new life. Pursued by the 'Cylons', 'Battlestar Galactica' travels during 'Centoni' to its new destination: a planet called Earth. Kids have their own tour through the cosmos with 'Zathura, A Space Adventure', a 'Jumanji'-style movie where each move of a table game faces the characters with a different astronomical event. Television also bowed to space adventures with classic series such as 'Lost in Space' (1965), 'Space 1999' (set on an outof-orbit and drifting satellite station in a distant and futuristic 1999) and the classic 'Star Trek' saga, a pioneer in many ways, and mainly in technological terms (for example, the warp propulsion system (see Figure 2).

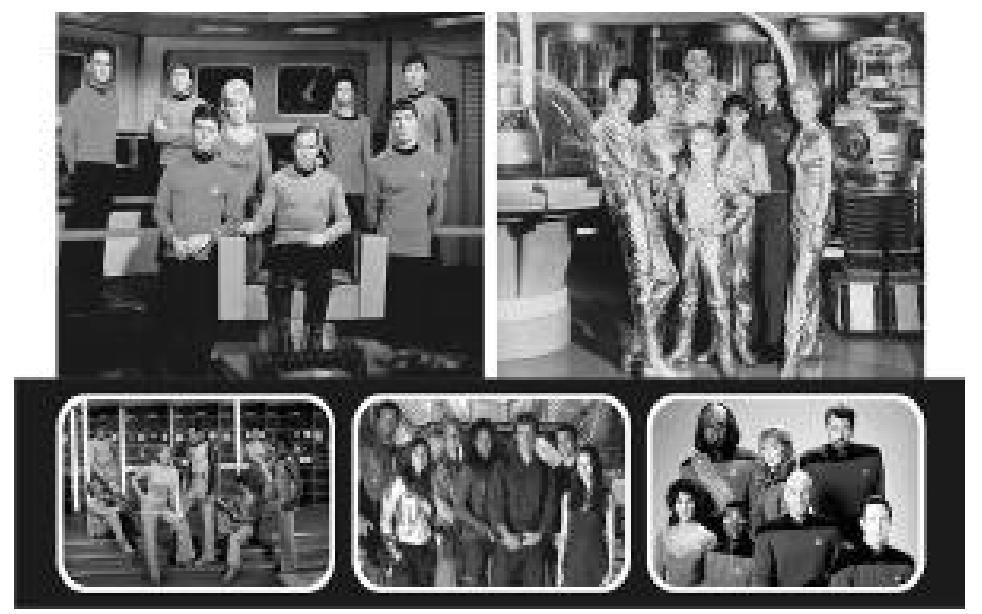

Figure 2. Travels and crews: Star Trek, Lost in Space, The Next Generation, Serenity, Space 1999

A ship equipped with a Warp Drive can travel at speeds several orders of magnitude greater than the speed of light, avoiding the problem of relativistic time dilation. Warp drive technology creates an artificial environment of normal space-time around the spaceship, a bubble, instead of entering a different dimension, as the hyperspace. Therefore, the warp-speed spacecraft may continue to interact with objects in normal space. The idea of a curved space as a means of propulsion has been 
360 Inspiration of astronomy in the movies: a history of a close encounter

studied by theoretical physicists, who have even designed hypothetical units impossible under current technology.

James Bond was also involved with space travel. In 'Moonraker' Michael Lonsdale plays a villain who creates a kind of Noah's Ark out of the world where there is only room for the beautiful; life on Earth, starting with all ugliness, will be annihilated. James Bond also stepped forward in time with the presentation of 'Quantum of Solace' (2008), a real tribute to astronomy and recognition of the location where the movie was filmed, the Cerro Paranal in Chile and the European Southern Observatory.

In a style closer to the thriller, Ridley Scott set a milestone with 'Alien' (1979). A commercial spacecraft with a crew of seven descends on an unknown planet and, without anyone noticing, a local predator enters the ship to eliminate all passengers, one by one. Only Sigourney Weaver survives, which allows her to re-appear in three sequels. 'Alien' had a predecessor in 1958: 'It! The Terror From Beyond Space', a science fiction B movie gem.

The psychological factor was also addressed by the cinema. In 'Event Horizon' a survey ship suddenly disappears and reappears near Neptune. A rescue team is assembled to help the crew. Upon arrival, rescuers find a huge, desolate warehouse where they discover evidence of the dreadful fate that surprised the occupants. This psychological horror movie shows evident traces of a classic in the genre: 'Solaris' by Andrei Tarkovsky, which marks a turning point in the story of speculative fiction, as the object and subject of study in the film is the human being itself and the functioning of the brain. This film had a remake thirty years later starring George Clooney, under the direction of Steven Soderbergh.

One of the most memorable space travel stories created by the movies is the one made by Ellie, the character played by Jodie Foster in 'Contact'. The protagonist builds a ship following the instructions received through radio waves emitted from another planet, and travels toward the star Vega making use of a hypothetical consequence of the theory of general relativity: wormholes. Using this property, Ellie makes a trip that would have needed 26 years, moving at the speed of light, but which takes only a few seconds to observers on Earth and 18 hours for the traveler.

On the other hand, the sky has always presented a display worthy of admiration. In 'Swades' (India, 2004), a crowd discovers the starry night from the hand of a NASA engineer who returns to his country and takes advantage of a power outage. This prevents people from seeing a 
and Raúl Gabellone

movie projected in the town square, but permits them to see the celestial wonders. Kevin Spacey also looked at the sky in 'K-Pax' from the planetarium at the Museum of Natural History in New York, but with the aim of finding his home in the Cosmos.

\section{The influence of the cinema in popular imagination:} highlight and hoax

In 1968, Stanley Kubrick surprised the world with '2001: A Space Odyssey', which became the classic of space travels. Keir Dullea travels for an endless ten minutes through a parade of kaleidoscopic images, after which he sees himself as an old man who, after his death, is reborn on his home planet: Earth. This movie was released in the 60s, the dawn of space exploration. The Earth's gravity is mimicked by a rotating wheel-shaped space station, for which Kubrick received advice from scientists. Following the calculation in diameter and adequate speed, the wheel was built, according to the appropriate scale model and shot revolving in real-time. The real International Space Station, which is still being built, is not a rotating wheel: it would be very expensive to keep it moving. '2001' marked a turning point not only in cinema but also in terms of how society perceived astronautics. The space race seemed to have a promising future, full of achievements and discoveries. Some milestones of the space race were reported by movies such as 'The Dish', an Australian comedy based on the work of Parkes Observatory astronomers who positioned their antennae to support the live broadcast of the moon landing. However, it is a fictional story, and hardly true to the real facts. ${ }^{3}$ The failed mission to the moon of Apollo XIII was dramatized in 1974 in a TV movie called 'Houston, we've got a problem' and was released for the big screen in 1995 in the very successful 'Apollo XIII', in which Tom Hanks, Bill Paxton and Kevin Bacon play the three astronauts who, in 1971, had to return without reaching their goal and were miraculously saved. The film 'Marooned' seems to have been premonitory, since it raised the possibility of a situation like that of Apollo 13 two years before it happened.

3 M. Din,'The Truth about the Dish' at http://members.pcug.org.au/ mdinn/TheDish/ [accessed 30 January 2011]; Anonymous, ‘The dish: Fact versus Fiction' at http://outreach.atnf.csiro.au/visiting/parkes/looselybased.html [accessed 30 January 2011]. 
362 Inspiration of astronomy in the movies: a history of a close encounter

In the 1980s, people questioned the trip to the moon after Hollywood launched 'Capricorn 1'. This movie tells the story of a supposed first manned trip to Mars; just before the launch, the crew is kidnapped and locked in a television studio, from where they will pretend to have arrived on Mars. When the astronauts realize that the rocket disintegrated in the air and that they shall be killed in order to cover up the fraud forever, they decide to flee, each one in a different direction in search for help (Figure 3).

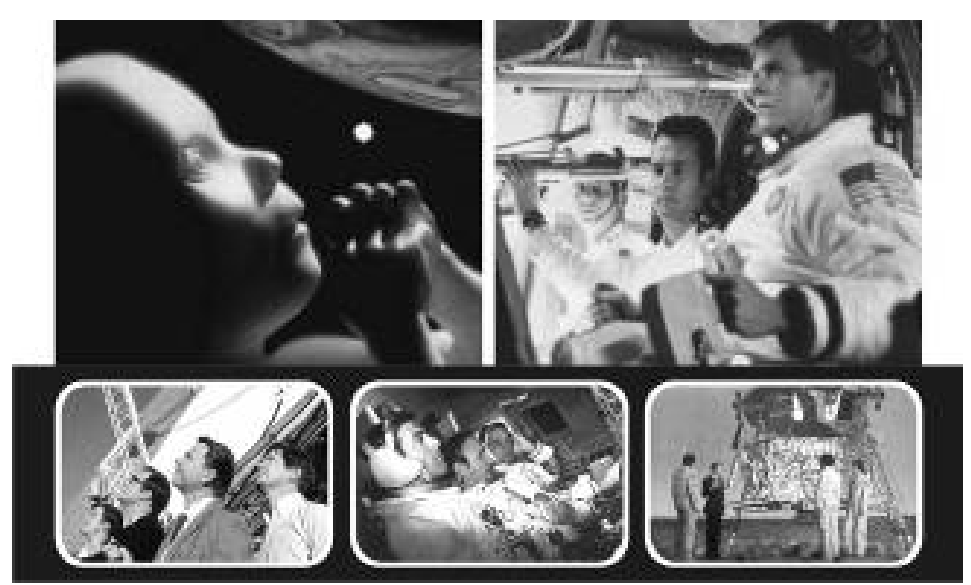

Figure 3. Highlight and Hoax: 2001, Apollo 13, Capricorn 1, Marooned, The Dish

Since Percival Lowell thought he discovered canals on Mars, the popular imagination flew toward the belief that a technical civilization existed on Mars, now or in the past. In 1898, H. G. Wells wrote 'War of the Worlds', a novel which posited the reaction of humankind against a Martian invasion; how, when everything seemed to succumb to the killer Martian heat-rays, bacteria broke down the invaders. This great story was filmed in 1953, and a recent remake directed by Spielberg includes abductions and cannibalism by Martians: modern times condition and provide new forms of imagination. In 1950, Ray Bradbury put together a series of stories related to Mars in the anthology 'The Martian Chronicles' which, although never brought to the big screen, was dramatized in 1980 in a three-episode mini-series for TV (Figure 4). 

and Raúl Gabellone

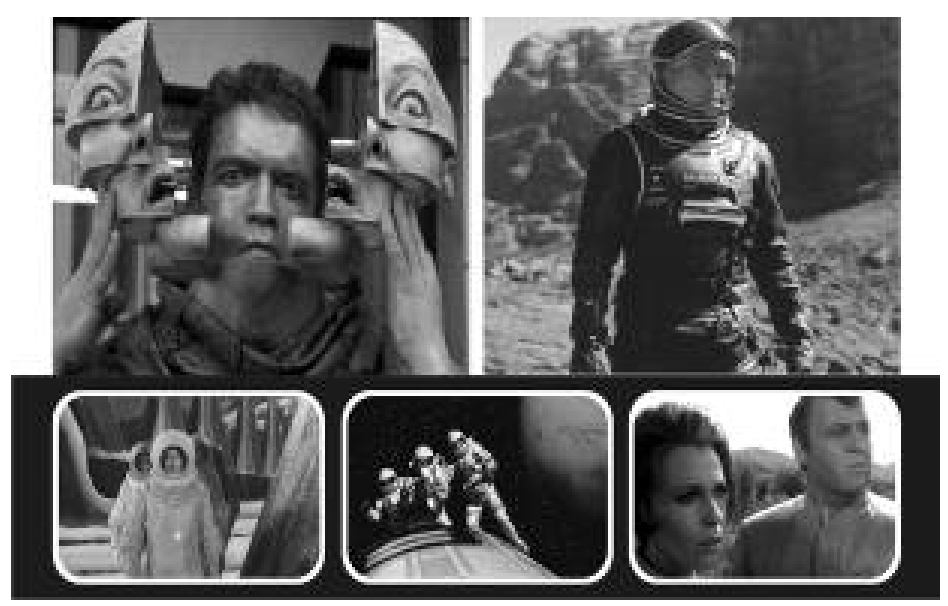

Figure 4. Destinations: Total Recall, Red Planet, The Illustrated Man, Mission to Mars, Flight to Mars

\section{Destinations: to be or not to be in space}

Mars was the destination that most captivated the imagination not only of book writers, but also of screenwriters. Already in 1938, the cinematic industry visited the red planet with 'Flash Gordon's Trip to Mars'. In 1950, in 'Rocketship X-M', Lloyd Bridges went to Mars by mistake, when his destination was the Moon. Only one year later, in 'Flight to Mars' the traveller is Cameron Mitchell, and for the first time, he goes 'in colour'. There was even a kind of Martian version of 'Castaway', entitled 'Robinson Crusoe on Mars' with an astronaut stranded on Mars. In 'Total Recall', based on Philip K. Dick's story 'We Can Remember It for You Wholesale', Arnold Schwarzenegger takes a trip to Mars and, to make the best possible use of it, acquires artificial memories from Mars recorded in his brain by the agency 'Total Recall'. The final transformation of the Martian atmosphere into an Earth-like atmosphere, and the consequent transformation of the planet into a new Earth, which in the film demands seconds, would take thousands of years in reality. Mars was revisited in 'Mission to Mars' and 'Red Planet', films which had the guidance of NASA and showed a more believable world, especially 'Red Planet', in which real images of recent missions to the planet were included.

In 1969, Rod Steiger starred in another Bradbury book made into a movie: 'The Illustrated Man', this time, included the tale of a trip to Venus. The story is set in a future when man has built solar shelters on 
364 Inspiration of astronomy in the movies: a history of a close encounter

Venus. Four astronauts are stranded, due to the breakdown of their ship, and must find shelter before the heavy and persistent rain kills them directly or drives them to commit suicide. In fact, these astronauts would not have needed much to kill themselves since, in addition to the unbearably high temperatures, raindrops on Venus carry sulphuric acid.

In addition to Mars and Venus, other places visited by Hollywood are the planets Jupiter in '2001', Saturn in 'Silent Running', Uranus in 'Journey to the Seventh Planet', Neptune in 'Event Horizon', the star Vega in 'Contact' and Europa, the moon of Jupiter, in '2010: The Year We Make Contact', (the sequel to '2001'). We see that destinations in more recent films are not like the Earth, but are consistent with recent findings: Europa, a moon with a crust of cracked ice containing a liquid water ocean underneath and Io, the most volcanically active body in the Solar System, both appeared in '2010'. Even Vega, where we cannot know if there are planets or not... the 'Vegans' display a terrestrial environment (Pensacola) to communicate with humans, in 'Contact'.

\section{The Sun and Moon, as main characters}

A mostly unusual destination is the Sun (Figure 5).

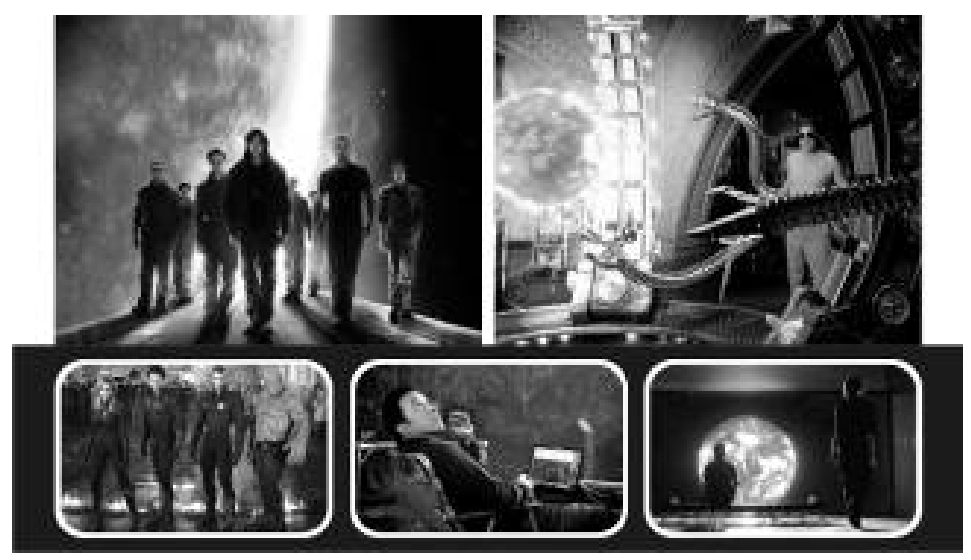

Figure 5. The Sun: Sunshine, Spider-Man 2, 2012, Fantastic 4

In 'Sunshine', an expedition must reach the dying Sun in order to reactivate the nucleus. Although the script is very hard to believe, this movie is topped with wonderful pictures of our star, recently acquired by the SOHO satellite. Another extinction of an artificial Sun, small but as efficient as the real one, appears in 'Spider-Man 2'. In this film, the Sun 

and Raúl Gabellone

is turned off simply by dropping it into a river. The solar wind has also been used in movies. This flow of particles from the sun that constantly runs through the Earth was the excuse to cause the genetic changes that gave extraordinary powers to the 'Fantastic Four'. Going even further, in '2012', the solar wind was accompanied by a very particular neutrino, which heated the Earth inside to the point of melting the core and turning the crust unstable. That, combined with extreme planetary alignments, the Solar System crossing the Galactic Plane, an interaction with an unknown planet (planet X, or Nibiru), and other impossible astronomical events, led to a series of disasters that nearly wiped out life on the planet.

Among the most breathtaking cosmic spectacles are total solar eclipses. Multitudes of eclipse hunters from around the world gather each time a total eclipse somewhere in the world is announced. In 'Dolores Claiborne', Kathy Bates uses the lack of witnesses and the momentary darkness to get rid of her abusive husband. An eclipse explains the appearance of a killer plant in the film 'Little Shop of Horrors', and is a very useful tool to provide the film with a credible ending, unlike, for example, that of 'When Dinosaurs Ruled the Earth'. In 'The Simpsons' an eclipse occurs just when a solar-powered monorail is out of control. In 'Tintin and the Temple of the Sun', Tintin and his friends are condemned to death and are saved by an eclipse. Something similar happens in 'Apocalypto' by Mel Gibson. In the Brazilian film 'House of Sand', the eclipse of 1919 is a protagonist of the story (Figure 6).

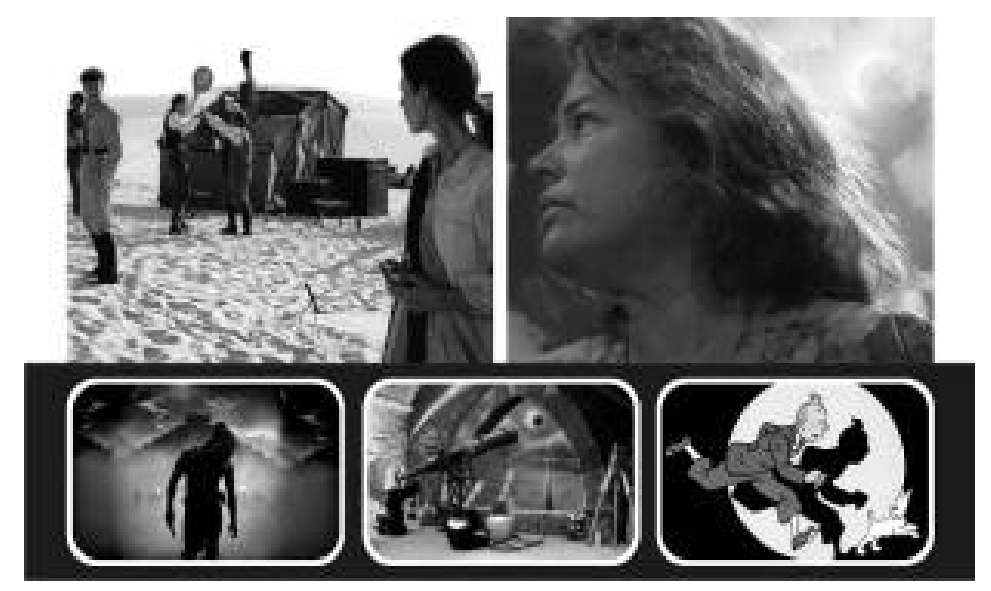

Figure 6. Eclipses: House of Sand, Dolores Claiborne, Tintin, The Eclipse, Apocalypto 
366 Inspiration of astronomy in the movies: a history of a close encounter

The charm of the full moon has also been used in movies, to the extent that in 'Apocalypto' it appears the night after the eclipse and, in 'Dolores Claiborne', the night before, despite the fact that a total solar eclipse and a full moon must be separated by a couple of weeks. In 'Moonstruck' a full moon triggers a series of blazing infatuations.

\section{Minor astronomical bodies}

There are various examples of minor astronomical bodies being used in films (Figure 7).

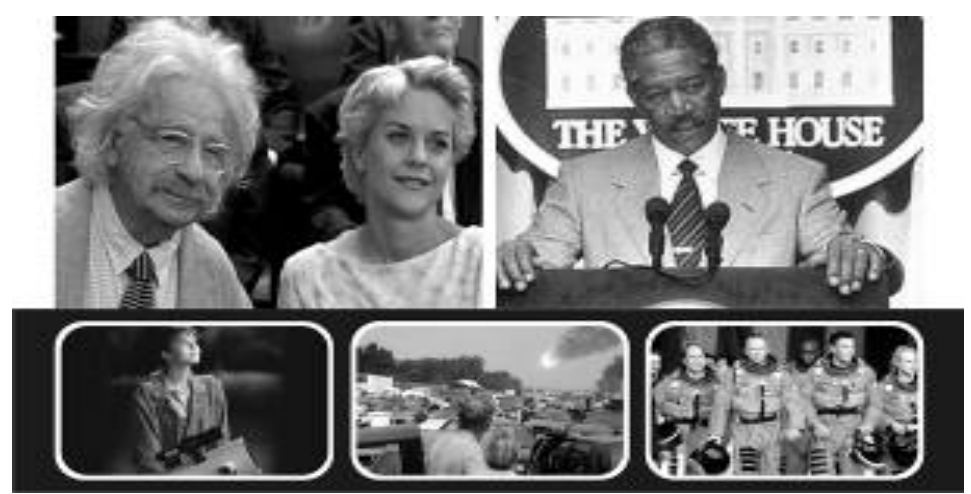

Figure 7. Small Bodies: IQ, Deep Impact, Armageddon, A Walk to Remember

Another great astronomical sight exploited by movies is comets, which are shown as beautiful and romantic as in 'Wimbledon' 'IQ' and 'A Walk to Remember', or become dangerous as they fall out of control. 'Meteoro' tells a story in which U.S. scientists have to convince the Russians to join the nuclear missiles that both governments have illegally launched into orbit to disintegrate the asteroid Orfeo, which threatens to collide in a few days with the Earth and destroy humankind. The collision produces avalanches, tsunamis, earthquakes and even a mudslide. In 1998, Hollywood released two films about asteroid collisions with the Earth: 'Armageddon' and 'Deep Impact'. In 'Armageddon' a Texas-sized asteroid threatens to crash in 18 days, and a group of scientists, geologists and astronauts, led by Bruce Willis, carry a nuclear warhead to fit in the centre of the asteroid and blow it to pieces. Further away from adventure and special effects, and in a much more 
and Raúl Gabellone

humanistic approach, 'Deep Impact' proposes to destroy the asteroid in the 'Armageddon' way, travelling to the comet's head to place explosives, but when the mission fails, it is accepted that a collision is inevitable and underground caves are built to shelter up to a million people, chosen by lot to save humanity. The idea is not new: in the 1951 classic 'When Worlds Collide', with the imminent collision between the Earth and the planet Zyra, astronomers build a rocket that only the lucky winners of the draw can access to restart their lives on another planet. Closer to our days, '2012' passes for the ark of salvation, offered for sale for those who can afford its high cost.

In the movie 'Asteroid', Anabella Sciorra plays an astronomer who works to break up an asteroid on a collision course with Earth, briefly saving millions of lives. Unfortunately, pieces of asteroid collide at different locations throughout the world. The disintegration of the meteorite, therefore, turns out to be counterproductive. It is interesting to notice that in this movie, the astronomer is shown not only as a scientist but also as an ordinary human being attempting to provide a service to humanity.

\section{The portrayal of astronomers}

In the origins of cinema, the image of the astronomer was stereotyped and unrealistic. Let us recall that in 'A Trip to the Moon' by Méliès, the astronomers look like a mix between magicians and Harlequins, with long beards, robes and bonnets. 'Stardust's' astronomer also has a long beard. In 'Addicted to Love' Matthew Broderick wears a T-shirt that makes it clear what his profession is. In 'The Simpsons', astronomers are ugly, with glasses and overalls...and very competitive! The protagonists of the TV show 'Rawhide' find it very difficult to decide on an appropriate costume when one of them has to pretend to be an astronomer to solve a crime.

In some movies, it is possible to understand the real life of an astronomer. Without any doubt, the movie that best represents the life of an observational astronomer is 'Contact'. The character played by Jodie Foster was inspired by a real person: the renowned astronomer Jill Tarter, who has been for years heading the Search for Extra Terrestrial Intelligence project, SETI. In 'Contact' it is possible to see how an astronomer must struggle to get grants to support his research, travel to different observatories in the world to acquire the observational data, and often fight against bureaucracy (Figure 8). 
368 Inspiration of astronomy in the movies: a history of a close encounter

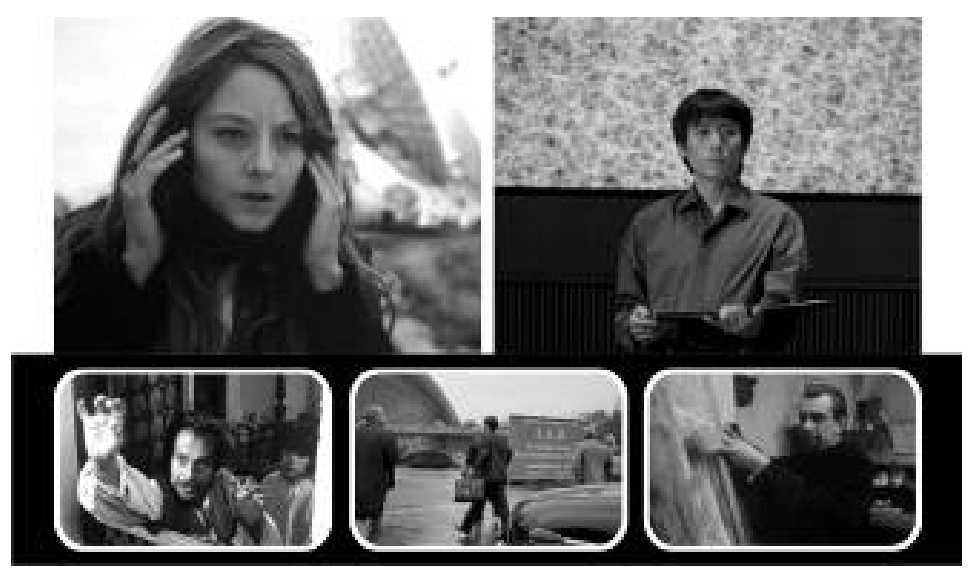

Figure 8. How to Portray an Astronomer and Biographies: Contact, Dark Matter, Kepler, The Promise, Galileo

'The Promise' by Margaret von Trotta, illustrates another case based on real life. The protagonist of the story is an astronomer expert in solar physics, and is separated from his wife and son by the Berlin Wall. Business trips will be an excuse for temporary reunions. In its storyline, some parts of the film are set at conferences that really took place, including the assembly of the International Astronomical Union in Prague in 1967.

'Dark Matter' tells the story of a Chinese student who comes to America to do his $\mathrm{PhD}$ thesis in cosmology. His research consists of numerically simulating the formation of galaxies incorporating dark matter into the models. The film shows the experiences of students who leave behind their families and their lives, adapting themselves to a new culture and different language, the enthusiasm for professional achievement, the competition, the pressures they suffer, especially when clashes with a mentor appear, and finally, the desperation when, as in this case, the greatest fear of all $\mathrm{PhD}$ students comes true: the disapproval of the dissertation. This film is based on the tragedy that unfolded in the University of Iowa in 1991.

'Contact', 'Dark Matter' and 'The Promise' are related to real lives, but the biographies of famous astronomers had no major impact on the film industry. The most renowned movie about an astronomer's biography is probably 'Giordano Bruno' (1973), with Gian Maria Volonte, mainly because of the tragic life of the monk, whose ideas were considered heretical back in 1600 . His theories of the possibility of life 

and Raúl Gabellone

on other worlds, the proposal of an infinite universe, or the heliocentric theory, led him to clashes with the Church. The astronomer who has been the subject of most films is Galileo; he was played by Cyril Cusack in 1969, Topol in 1975, and Michael Moriarty in 1998, but all these films went unnoticed. ${ }^{4}$ In 1974 a biography of Kepler, one of the greatest astronomers, was shot in the former East Germany, but was distributed only in the communist bloc. It shows the astronomer when, while outlining the laws of planetary motion, he was fighting to save the life of his mother. He was accused of witchcraft, and, in turn, dreamt of the time when science would drive the progress of humanity.

\section{Observatories: not only buildings}

Probably because of its proximity to Hollywood, one of the most commonly shown observatories is the Griffith Observatory in Los Angeles. We see it in a number of movies like 'Rebel Without a Cause', 'Rocketeer', 'Bowfinger', 'Transformers', 'Charlie's Angels' and 'Terminator'. The Adrian Peak Observatory in Texas, which appears in 'Deep Impact', is actually the Mount Wilson Observatory in Pasadena, near Los Angeles, the same shown in 'K-Pax'. Other observatories represented in films are those with radio telescopes. The most famous is the Very Large Array (VLA), a set of 27 antennas arranged in a ' $\mathrm{Y}$ ' shape in the plains of New Mexico, United States, which was the setting of 'Contact', '2010' and 'Independence Day'. The 300-metre diameter antenna of Arecibo, in Puerto Rico, also appears in 'Contact' and is destroyed in the James Bond film 'Goldeneye'. The 64-meter antenna of Parkes, Australia, is the main character of 'The Dish', a movie which shows the complications that are generated by one of the greatest enemies of the radio astronomical observation: the wind. The IAR (Argentine Institute for Radio astronomy) antennae also served as a background for an Argentinean film 'Small Miracles', by Eliseo Subiela. The lodge of the European Southern Observatory in Atacama is the scenario for 'Quantum of Solace', the latest James Bond movie (see Figure 9).

4 C. Olivotto and A Testa, 'Galileo at the cinema', in The Global and the Local: The History of Science and the Cultural Integration of Europe in M. Kokowski (ed.), Proceedings of the 2 ICESHS (Cracow, Poland, September 6-9, 2006), pp. $178-180$ at http://www.2iceshs.cyfronet.pl/2ICESHS_Proceedings/Chapter_8/RE_Olivotto Testa.pdf. 
370 Inspiration of astronomy in the movies: a history of a close encounter

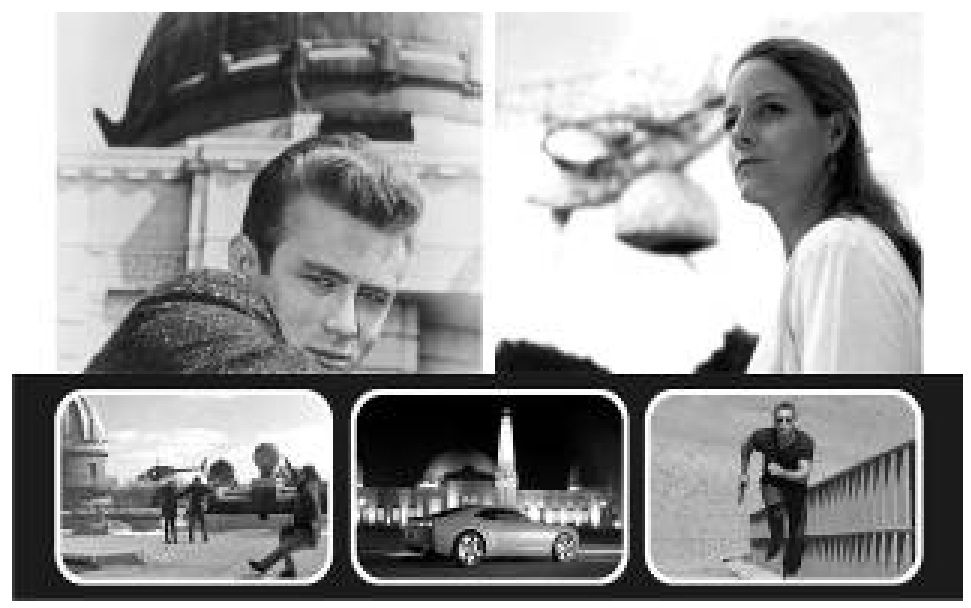

Figure 9. The Observatories: Griffith, Arecibo, VLT

\section{Astronomy and astronomers in comedy}

Astronomy and astronomers are not always taken seriously. The astronomer in the 'Pink Panther' episode 'Twinkle, Twinkle, Little Pink' displayed an extensible telescope, and it was very difficult to withdraw from the collective imagination the idea that telescopes can be stretched. In the comedy 'Addicted to Love', Matthew Broderick is an astronomer in love with Meg Ryan, and uses the telescope to see his girlfriend in the Park at a fixed time every the day. We also recall the Simpson Observatory in 'Scuse Me While I Miss the Sky', which draws attention to light pollution, an issue completely absent in fiction. In 'Way...Way Out', Jerry Lewis is sent on a mission to a weather station on the Moon. The background of the Cold War is always present, and there is a funny fight with a Russian cosmonaut in the weak gravity of the Moon. In 'Space Cowboys', three retired astronauts are returning to space on a mission that none of their working colleagues are able to comply with. 'Amazon Women on the Moon' is a collection of unconnected stories, interspersed with scenes of a low budget film in which three astronauts arrive on a Moon populated by women. Parodied situations of Méliès' films are easily recognizable. 'The Hitchhiker's Guide to the Galaxy' takes us on a crazy journey through the universe, to witness the destruction of Earth by a bureaucratic error, and its reconstruction from the memories of an earthling. The planet turns out to be the ideal world that many people would like (Figure 10). 


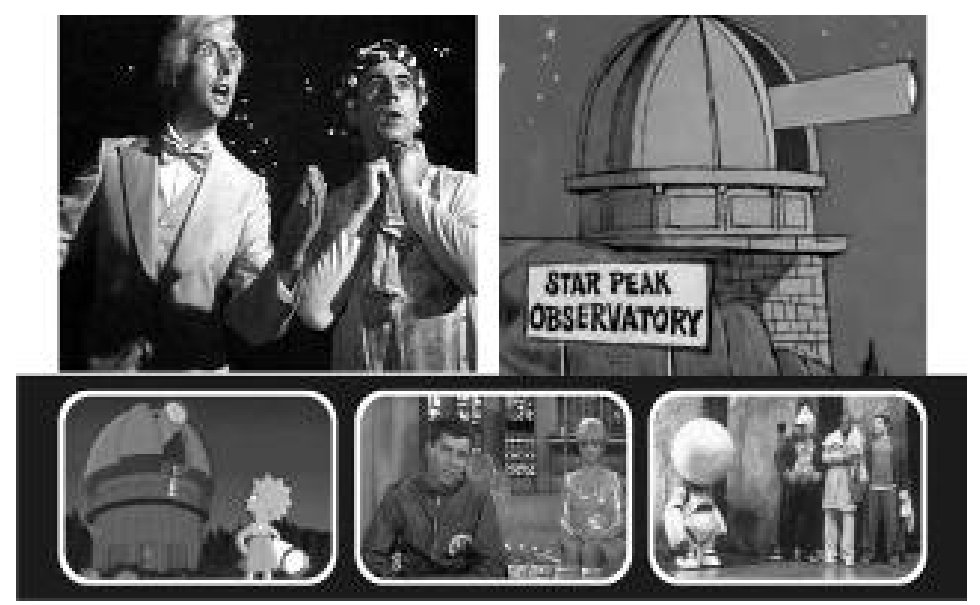

Figure 10. Astronomy in beat of comedy: The Meaning of Life, Pink Panther, The Hitchhiker's Guide to the Galaxy, Way...Way Out, The Simpsons.

\section{Conclusion}

Closing this incomplete 'astronomy guide in movies', we should mention perhaps the ultimate anthology scene: the 'Galaxy Song' in Monty Python's 'The Meaning of Life', which summarizes with scientific precision what astronomy is, and what is its use. It places humans in a vast universe, a perspective that leads us to believe that each of us plays a role in the machinery of the cosmos and, at the same time, shows that nothing is too important, that perhaps things work in spite of ourselves, and that the power of science and, why not, humour, can make it evident to us. Movies reflect our lives, our fears, dreams, hopes, and achievements. Myths, legends and tales were used across the ages to transmit our feelings and knowledge and nowadays, renewed, they appear in movies. 